\title{
Effect of mobile frequencies exposure on histology of retina and cornea in pregnant albino mice
}

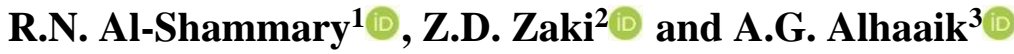 \\ ${ }^{1}$ Department of Physics, College of Education for Pure Science, University of Mosul, ${ }^{2}$ Department of Dentistry, Al-Noor \\ University College, ${ }^{3}$ Department of Anatomy, College of Veterinary Medicine, University of Mosul, Mosul, Iraq
}

\begin{tabular}{l} 
Article information \\
\hline Article history: \\
Received April 10, 2021 \\
Accepted May 26, 2021 \\
Available online December 20, 2021 \\
\hline Keywords: \\
Mobile phone radiation \\
Retina \\
Cornea \\
Histological effects \\
\\
\hline Correspondence: \\
A.G. Alhaaik \\
alhaaik_ag@uomosul.edu.iq
\end{tabular}

\begin{abstract}
In the current study, the potential effects of the Nokia mobile device were studied with frequency 900-1800 Mhz on the eyes of pregnant and non-pregnant female Swiss mice. The mice were divided into three groups: The first group is a control group consisting of five mice, the second group consists of 10 mice and the third group consists of 10 pregnant mice. Female mice of the second and third groups were exposed for a 3 hour / day and for a 30 days to a mobile device. After the end of 30 days, mice were euthanized and tissue samples were taken from the eyes of pregnant and non-pregnant mice. Microscopic examination showed, that there are significant effects on the cornea and retina of the eye, especially in pregnant females, which supports the current studies conducted on the effect of mobile phones on the eyes represented by vascularization where some sections showed newly formed blood vessels in stroma layer just beneath bowman's membrane and retina degeneration. This study concluded that the exposure to the mobile radiation led to serious histological changes in the tissues of eye which may lead to blindness.
\end{abstract}

DOI: 10.33899/ijvs.2021.129839.1701, (CAuthors, 2022, College of Veterinary Medicine, University of Mosul.

This is an open access article under the CC BY 4.0 license (http://creativecommons.org/licenses/by/4.0/).

\section{Introduction}

The excessive use of communication devices has led to the appearance of many important studies on the potential health effects of these devices on the human body (1). It has been found that many modern devices such as mobile phones, radars, and radio and television transmitters emit electromagnetic radiation (2).

The mobile phone system was previously an analog system with frequency 450-900 MHz, but now, after recent development, the digital system is used at a frequency higher than 1800-1900 MHz. As a result of the emergence of health effects resulting from exposure to these rays emitted from mobile phones, many studies were conducted on this topic (2). Due to of eye sensitivity to this type of radiation, many studies had shown the presence of potential complications after direct irradiation, especially the case of cataract generation (3).
It was also found that exposure of the body to microwaves leads to an increase in the temperature inside the living tissues as a result of the thermal effect of radiation (4). Others found in their study on chicken embryos that the electromagnetic waves emitted from the mobile phone caused derangement in the retinal differentiation of these embryos (5). Mobile phone may cause blurring of vision, inflammation, secretion and lacrimation of the eyes, they observed also that mobile phone cause derangement of retinal differentiation in animal (6).

In addition, using of mobile phones caused blurring of vision, redness of the eyes, vision disturbance, secretion of the eyes and inflammation in the eyes of mobile phone users women or men (7). Nassar et al. (8) found that 900$1800 \mathrm{MHz}$ non-ionizing radiation of the mobile phone has a marked degenerative effect on the retina of developing albino mice at the ultra-structural level, they added that all 
the retinal layers exhibited a reduction in their height and cell population. In the same manner, $900 \mathrm{MHz}$ mobile phone like RF radiation caused noticeable differences between photoreceptors of retina of the control and exposed mice as bleaching of photoreceptors in the exposed mice (9).

Current study aimed to focus on the effect of mobile phone radiation on the histological architecture of retina and cornea in pregnant and non-pregnant female mice.

\section{Materials and methods}

\section{Animals and experimental design}

In this study, 25 adult Swiss female mice were used to achieve comparison between control group and pregnant and non-pregnant mice. The mice were placed under conditions of temperature $20-25^{\circ} \mathrm{C}$ and 12 hours of darkness, 12 hours of light (10).

The mice divided into three groups. The first group includes five females, set as control group without exposure to radiation, the second group included 10 non pregnant females, and the third group also included 10 pregnant females. The second and third groups were exposed to radio frequencies from the mobile device for 30 days, 3 continuous hours per day. All aggregates are placed in specially designed plastic cages to allow for good ventilation and free movement.

\section{The exposure setup}

Animals were exposed using mobile phone radiation (Nokia, model 1280, MPN HKCRN1280BK, China) at a specific absorption rate (SAR) of $0.78 \mathrm{~W} / \mathrm{kg}$ and frequencies from 900 to $1800 \mathrm{MHz}$ at a density of $500 \mu \mathrm{W} /$ $\mathrm{cm} 2$. The two devices were installed approximately $10 \mathrm{~cm}$ above the cage by means of a stand Railing. Exposure was continued daily ( 3 hours / day) and the two cell phones were set to dialing mode in order to send and receive waves during communication (11).

\section{Histological techniques}

The eyes were harvested from each group, and processed for light microscope examination by using routine histological processing method (12). Specimens of eye were fixed in Davidson's Fluid for 24 hrs. then transferred to $10 \%$ neutral buffered formalin solution for $48 \mathrm{hrs}$. The specimens then processed to prepare $5 \mu \mathrm{m}$ thick paraffin sections and stained with Harris Hematoxylin and Eosin (13).

Quantitative analysis was performed in the stained sections; the thickness of retina and cornea was measured $/ \mu \mathrm{m}$ by using OMAX 5.0MP Digital USB Microscope Camera with advanced picture analysis software (ToupView). The software of camera was calibrated to the lenses of Olympus-CX31 Microscope by aid of $0.01 \mathrm{~mm}$ calibrating slide (ESM-11 / Japan) (14).

\section{Results}

Histological sections of cornea of control group showing the normal histological structure of corneal layers which composed from: anterior epithelium, anterior limiting membrane, stroma, posterior limiting membrane and the posterior epithelium (Figure 1A).

Histological section of retina of control group showing the normal histological structure of retinal layers which included: photoreceptor cells (rod and cones), outer nuclear layer, outer plexiform layer, inner nuclear layer, inner plexiform layer and ganglionic cell layer (Figure 1B).

The histological investigation of cornea in exposed pregnant female mice (group 2) revealed a variable degrees of corneal histological changes represented by vascularization where some sections showed newly formed blood vessels in stroma layer just beneath bowman's membrane (Figure 2). Whereas in other sections there was congested blood vessels in the stromal layer with degenerated collagen fibers (Figures 3 and 4). The anterior corneal epithelium showed thickening on the tear film of squamous cell layer, in addition, the based cells and polygene cells of anterior epithelium showed signs of pyknotic nuclei (Figure 3).

The retina of female mice (group 3) exposed to the mobile radiation showed different histopathological changes represented by vacuolar degeneration of photoreceptor cells (rods and cons) especially in the outer segment of this layer (Figure 5). The exposed group 3 showed disorganization and vacuolar degeneration and necrosis in the outer nuclear layer was seen in the retina of females subjected to mobile radiation (Figure 6). Other sections of the exposed pregnant female mice showing necrosis and complete disappearance or depletion of photoreceptor cells (rods and cones) in the retina (Figures 7 and 8).
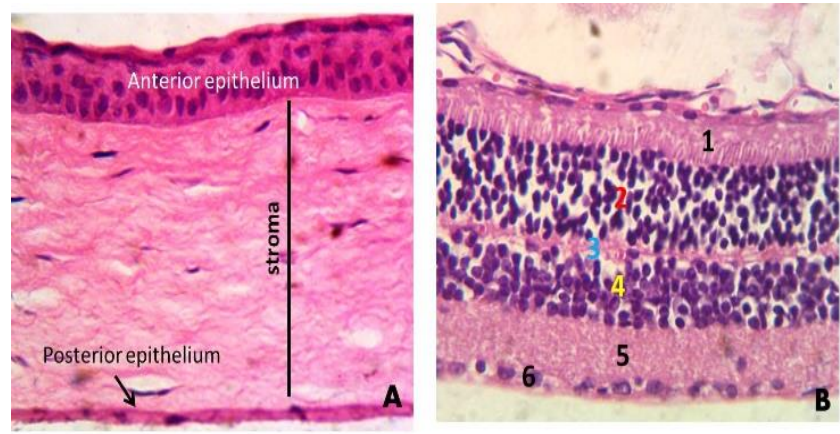

Figure 1: (A) histological section of corneal of normal control group shows the layers of cornea. (B) histological section of retina of normal control group shows the different layers of retina: 1 - rods and cons, 2- outer nuclear layer, 3- outer plexiform layer, 4-inner nuclear layer, 5inner plexiform layer, 6- ganglionic layer (HE 400X). 


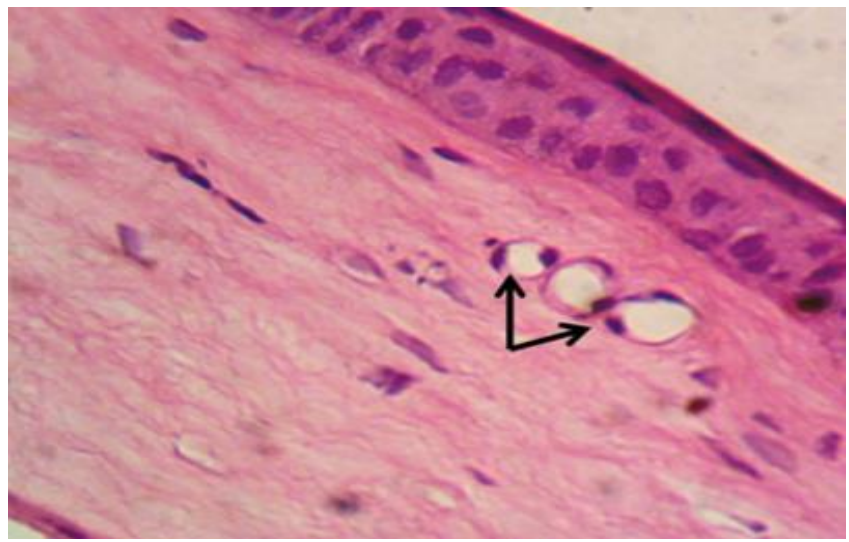

Figure 2: Histological section of cornea of group 2. Note the newly formed blood vessels in the stroma beneath anterior epithelium (arrows) (HE 400X).

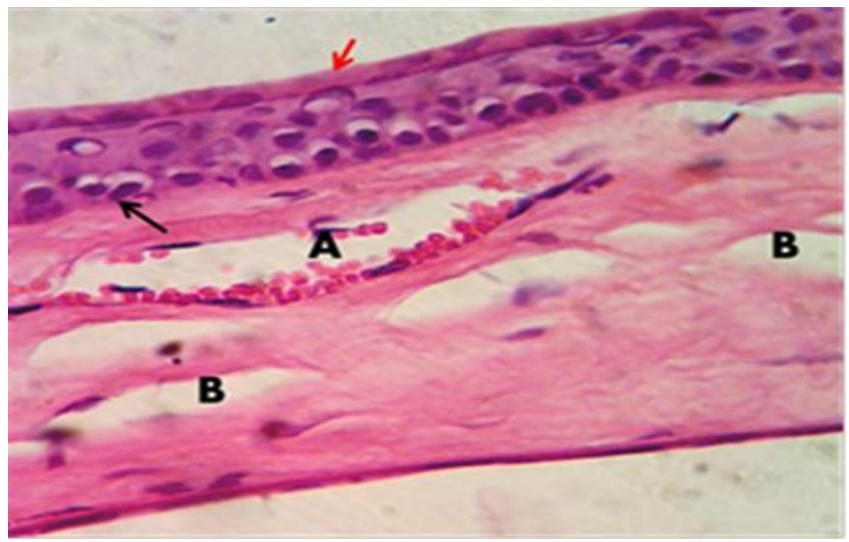

Figure 3: Histological sections of cornea of treated group 2 shows, (A) congested blood vessel, (B) edema among collagen fibers, (red arrow) thick of tear film of anterior epithelium, (block outer) pyknotic nuclei (HE 400X).

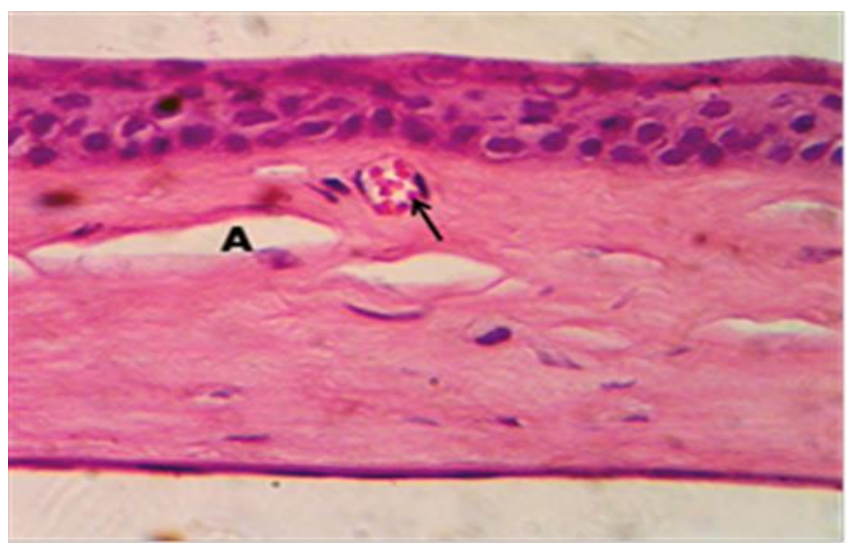

Figure 4: Histological sections of cornea of treated group 3 showed congested blood vessels (arrow) and (A) edema (HE 400X).

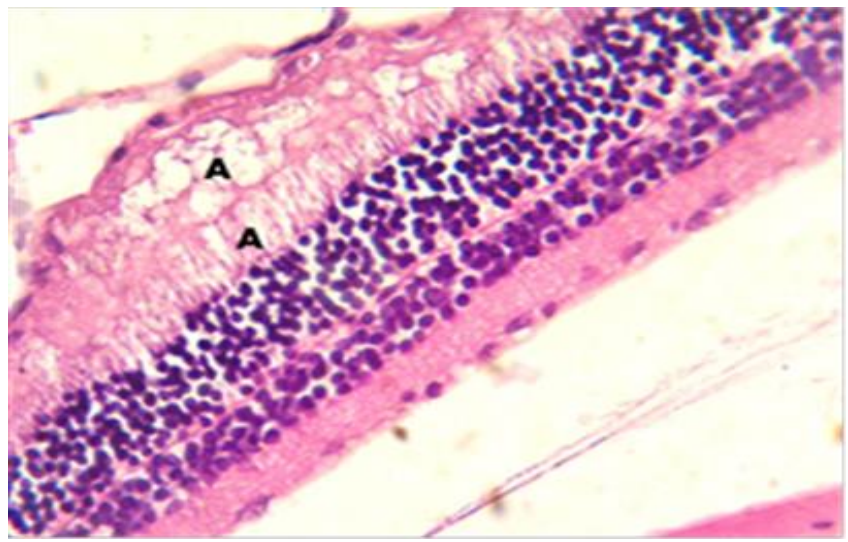

Figure 5: Histological sections of retina of exposed group 3, shows obvious vacuolar degeneration in the layer of roods and cons (A) (HE 400X).

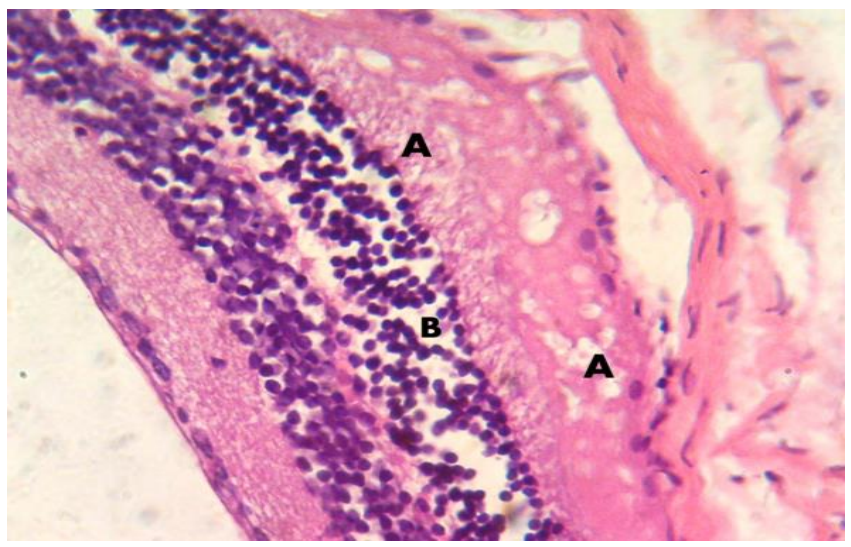

Figure 6: Histological sections of retina of exposed group 3, shows obvious vacuolar degeneration in the layer of roods and cons (A), disorganization and degeneration of outer nuclear layer (B) (HE 400X).

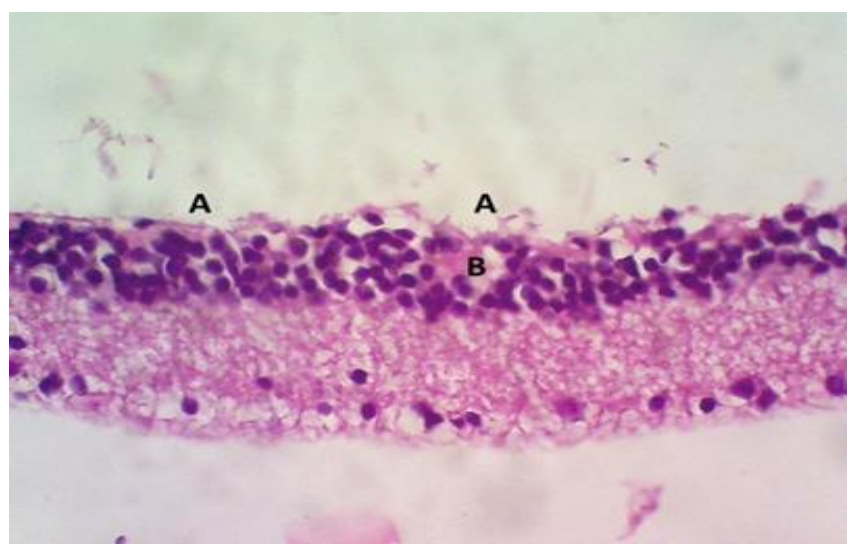

Figure 7: Histological section of retina of female group 2, note the complete disappearance of photoreceptor cells (A) necrotic focci in outer nuclear layer (B). (HE 400X). 


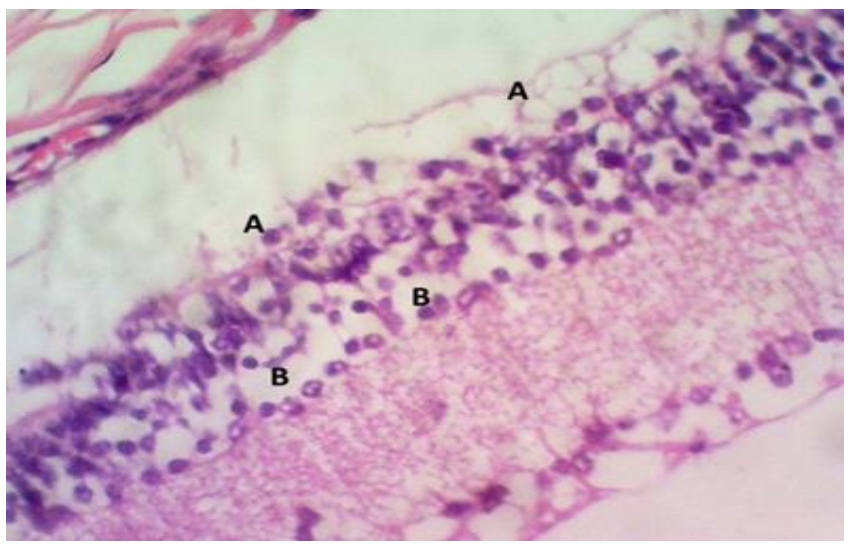

Figure 8: Histological section of retina of exposed female group 2, note the complete disappearance of photoreceptor cells (A) necrotic focci in outer nuclear layer (B). (HE 400X).

\section{Discussion}

The current study describes the histological changes of radiation-induced corneal and retinal damage to the mice eye. When exposed to radio waves of a mobile device, there are two types of effects (thermal and non-thermal) (4). In the case of the eye, it is likely to be exposed to direct damage due to its limited blood supply (6), in addition to that, it is not protected by the skull as is the case for the brain. Since the retina is very sensitive, it may be exposed directly to radio radiation due to the polar characteristic of the photoreceptor cells as well as to its high water content (15). Several studies have shown that there is a relationship between damage to the retina of the eye and exposure to electromagnetic radiation which is consistent with our current study (16). It has been found that there is a serious health effect on the plasma protein and the eyes of newborn mice as a result of exposure to radio frequencies at 900$1800 \mathrm{MHz}$ emitted from mobile phones (6). The results showed that there are many pathological changes in the eye mainly represented by degenerated, hemorrhagic areas and detachment in some layers of the eye with alteration in collagen, most eye layers of the exposed group showed reduced staining affinity of polysaccharides especially in the photoreceptors (17). Khalil (9) found that exposure to radiofrequency radiation frequency at $900 \mathrm{MHz}$ for a month at a rate of 30 minutes/day caused clear differences in the photoreceptors of the retina between the control and exposed group 2 and 3 to radiation such as bleaching photoreceptors. Besides, that the retinal and corneal injury due to radiation included in dog retinal degeneration, vasculopathy and arteriosclerosis were recognized histologically and became more severe with time progress (18). In human, similar results have been proved to have different latency times ranging from 1-3 years with advanced deterioration and slight regeneration $(19,20)$.

\section{Conclusion}

This study concluded that the exposure to the mobile radiation led to serious histological changes in the tissues of eye which may lead to blindness represented by vascularization where some sections showed newly formed blood vessels in stroma layer just beneath bowman's membrane and retina degeneration.

\section{Acknowledgements}

The authors are grateful to the College of Veterinary Medicine, University of Mosul, for the assistance and cooperation.

\section{Conflict of interest}

Authors declared that there is no conflict of interests.

\section{References}

1. George DF, Bilek MM, McKenzie DR. Non-thermal effects in the microwave induced unfolding of proteins observed by chaperone binding. Bioelectrom. 20082 (4):324-330. DOI: 10.1002/bem.20382

2. Fawzy M. Possible impact (s) of cell phone electromagnetic radiation on human sperm parameters. Human Androl. 2013;2 (2):49-55. DOI: 10.1097/01.XHA.0000415089.15301.51

3. Mohammad RT, Ali S, Hossein N, Seyed M J, Alighanbari A, Mohammad R. The effects of microwave radiation on rabbit's retina. J Curr Ophth. 2018;30:74-79. DOI: $10.1016 / j . j o c o .2017 .08 .010$

4. Moulin VJ, Dube J, Rochette-Drouin, O, Levesque P, Gauvin R, Roberge CJ, Auger FA, Goulet D, Bourdages M, Plante M, Germain L. Electric potential across epidermis and its role during wound healing can be studied by using an reconstructedhuman skin. Adv Wound Care. 2012;1:81-87. DOI: 10.1089/wound.2011.0318

5. Zareen N, Khan M and Minhas L. Derangement of chick embryo retinal differentiation caused by radiofrequency electromagnetic fields. Cong anom. 2012;49:15-9. DOI: $10.1111 / \mathrm{j} .1741-$ 4520.2008.00214.x

6. Balik HH, Turgut- Balik D, Balikci K, Ozcan IC. Some ocular symptoms and sensations experienced by long term users of mobile $\begin{array}{llll}\text { phone. Pathol. } & \text { Biol. 2005;53(2):88-91. DOI: }\end{array}$ 10.1016/j.patbio.2004.03.012

7. Kucer N. Some ocular symptoms experienced by users of mobile phones. Electromagn Biol Med. 2008;27(2):205-209. DOI: 10.1080/ 15368370802072174

8. Nassar SA, Emam NM, Eid FA, Mohammed WT. Effects of nonionizing radiation on the ultrastructure of the retina of albino mice. $\mathrm{J}$ Amer Sci. 2011;7(12):1196-1208. [available at]

9. Khalil A, Al-Adhammi M, Al-shara B, Gagaa M, Rawshdeh A, Alshamli A. Histological and ultrastructural analyses of male mice exposed to mobile phone radiation. J Toxic Rev. 2012;1(1):1-6. [available at]

10. Baidaa A. barwarei, Hanan S. Sadoon. Histopathological and some biochemical effects of platinum drug on the liver and kidney of pregnant mice Mus musculus and their embryos. Iraqi J Vet Sc, 2020; 35(2): 291-300. DOI: 10.33899/ijvs.2020.126793.1382

11. Al-Chalabi AS, Asim R, Rahim H, Abdul Malek MF. Evaluation of the thermal effect of LTE $2600 \mathrm{MHz}$ (4G) electromagnetic field (EMF) exposure: Thermographic study on rats. Iraqi J Vet Sc. 2021;35(2):279-285. DOI: 10.33899/IJVS.2020.126787.1379 
12. Saevan S. Al-Mahmood. Improving light microscopic detection of collagen by trichrome stain modification. Iraqi J Vet Sc, 2020; 34(2): 273-281. doi: 10.33899/ijvs.2019.126176.1256

13. Theory and practice of histological techniques. 5th ed. London: Churchill Livingstone; 2002. 150-152 p.

14. Al-Haaik AG. A gross anatomical and histological study of pancreas in adult Kestrel (Falco tinnunculus). Iraqi J Vet Sc, 2019; 33(2): 175180. doi: 10.33899/ijvs.2019.162960

15. Kovacs E, Savopol T, Dinu A. The polar behavior of frog photoreceptors. Biochim Biophys. 1995;1273:217-222. DOI: $10.1016 / 0005-2728$ (95)00145-X

16. Youssef PN, Sheibani N, Albert DM. Retinal light toxicity. Eye. 2013;25(1):1-14. DOI: 10.1038/eye.2010.149

17. Eid F, Abou Zeid M, Hanafi N, El-Dahshan A. Mobile phone radiation induced plasma protein alterations and eye pathology in newly born mice. Egyp J Hosp Med. 2013;52:573-593. DOI: 10.12816/0000594

18. Ching S, Gillette S M, Powers B, Roberts S, Gillette E, Withrow S. Radiation-induced ocular injury in the dog: A histological study. IJRO. 1990;19(2):321-328. DOI: 10.1016/0360-3016 (90)90540-Z

19. Midena E, Segato T, Piermarocchi S, Corti L, Zorat PL, Moro F. Retinopathy following radiation therapy of paranasal sinus and nasopharyngeal carcinoma. Retina. 1987;7:142-147. DOI: $10.1097 / 00006982-198700730-00002$

20. Palva M, Palkama A. Ultrastructural lens changes in $\mathrm{x}$ ray induced cataract of the rat. Acta Ophthalmol. 1978;56:587-598. DOI: $10.1111 / j .1755-3768.1978 . t b 0137$ 1.x



روعة ناجي الثمري'، زينة ضبيان محمد زكي و عمار غانم

الحائك" ناعن

'قسم الفيزياء، كلية التربية للعلوم الصرفة، جامعة الموصل، بقسم طب

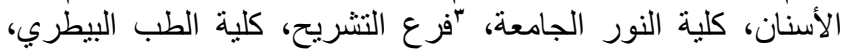

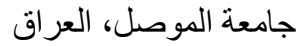

الخلاصة

في هذا البحث، تمت در اسة التأثيرات المحتملة لجهاز الهاتف النقال

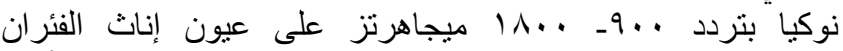

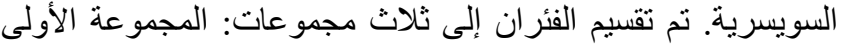

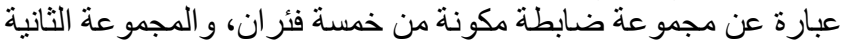

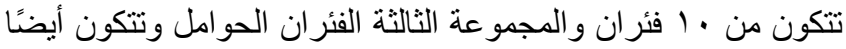

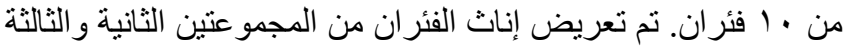

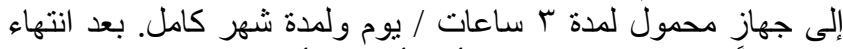

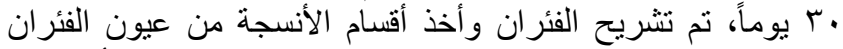

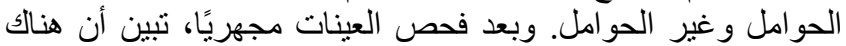

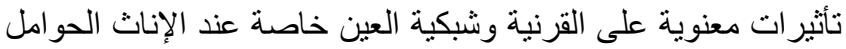

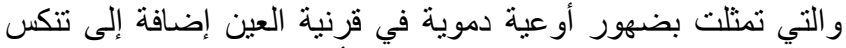

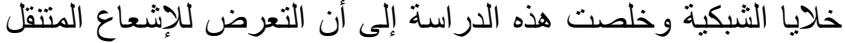

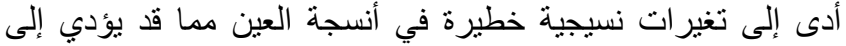

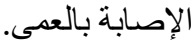

